\title{
Borderline ovarian tumors: clinical characteristics, management, and outcomes - a multicenter study
}

\author{
Mehmet Gokcu', Kemal Gungorduk2 ${ }^{2}$, Osman Aşıcıoğlu ${ }^{3}$, Nilüfer Çetinkaya ${ }^{4}$, Tayfun Güngör ${ }^{4}$, Gonca Pakay ${ }^{5}$, \\ Zeliha Fırat Cüylan ${ }^{4}$, Tayfun Toptaş ${ }^{6}$, Ramazan Özyurt ${ }^{7}$, Elif Ağaçayak ${ }^{8}$, Aykut Ozdemir $^{9}$, Onur Erol ${ }^{10}$, Anıl Turan $^{11}$, \\ Varol Gülseren ${ }^{1}$, Mehmet Sait İcen ${ }^{8}$, Taylan Şenol ${ }^{5}$, Hakan Güraslan ${ }^{9}$, Burcu Yücesoy ${ }^{8}$, Ahmet Sahbaz ${ }^{11}$, \\ Ozgu Gungorduk', Berhan Besimoğlu ${ }^{3}$, Kaan Pakay ${ }^{5}$, Osman Temizkan $^{3}$, Muzaffer Sancı ${ }^{1}$, Tayup Şimşek ${ }^{6}$, \\ Mehmet Mutlu Meydanlı ${ }^{4}$, Mehmet Harma ${ }^{11}$, Levent Yaşar ${ }^{9}$, Birtan Boran ${ }^{7}$, Aysel Derbent Uysal ${ }^{10}$ \\ and Ateş Karateke ${ }^{5}$
}

\begin{abstract}
Background: The optimal surgical management and staging of borderline ovarian tumors (BOTs) are controversial. Institutions have different surgical approaches for the treatment of BOTs. Here, we performed a retrospective review of clinical characteristics, surgical management and surgical outcomes, and sought to identify variables affecting disease-free survival (DFS) and overall survival (OS) in patients with BOTs.

Methods: A retrospective review of ten gynecological oncology department databases in Turkey was conducted to identify patients diagnosed with BOTs. The effects of type of surgery, age, stage, surgical staging, complete versus incomplete staging, and adjuvant chemotherapy were examined on DFS and OS.

Results: In total, 733 patients with BOTs were included in the analysis. Most of the staged cases were in stage IA (70.4\%). In total, 345 patients underwent conservative surgeries. Recurrence rates were similar between the conservative and radical surgery groups (10.5\% vs. $8.7 \%)$. Furthermore we did not find any difference between DFS ( $H R=0.96 ; 95 \%$ confidence interval, $\mathrm{Cl}=0.7-1.2 ; p=0.576)$ or OS ( $\mathrm{HR}=0.9 ; 95 \% \mathrm{Cl}=0.8-1.1 ; p=0.328)$ between patients who underwent conservative versus radical surgeries. There was also no difference in DFS (HR $=0.74 ; 95 \%$ $\mathrm{Cl}=0.8-1.1 ; p=0.080)$ or OS ( $\mathrm{HR}=0.8 ; 95 \% \mathrm{Cl}=0.7-1.0 ; p=0.091)$ between complete, incomplete, and unstaged patients. Furthermore, receiving adjuvant chemotherapy $(C T)$ for tumor stage $\geq I C$ was not an independent prognostic factor for DFS or OS.

Conclusions: Patients undergoing conservative surgery did not show higher recurrence rates; furthermore, survival time was not shortened. Detailed surgical staging, including lymph node sampling or dissection, appendectomy, and hysterectomy, were not beneficial in the surgical management of BOTs.
\end{abstract}

Keywords: Borderline ovarian tumor, Adjuvant chemotherapy, Surgery

\footnotetext{
* Correspondence: maidenkemal@yahoo.com

${ }^{2}$ Department of Gynecology and Gynecologic Oncology, Mugla Sıtkı Kocman

University Education and Research Hospital, Mentese 48000, Mugla, Turkey

Full list of author information is available at the end of the article
} 


\section{Background}

Taylor first described a type of ovarian tumor in 1929 that was different from both benign and malignant epithelial ovarian tumors [1]. Then, in 1973, the World Health Organization (WHO) assigned the name 'borderline' to these tumors, with morphological criteria (especially the absence of stromal invasion) [2]. Borderline ovarian tumors (BOTs) are currently staged according to the International Federation of Gynecology and Obstetrics (FIGO) classification of ovarian cancer; they represent $\sim 10-20 \%$ of all ovarian neoplasias [3]. They are diagnosed in younger women, at an earlier stage, and have a better prognosis than malignant ovarian tumors [4]. The 5-year survival rates are 95-97 \% and $70 \%$ of these tumors are stage I at the time of diagnosis [3].

Preoperative diagnosis of BOTs remains difficult [5]. Cancer antigen 125 (CA-125) is the most helpful available marker in the diagnosis of advanced-stage cases [6]. Moreover, the optimal surgical management and staging of BOTs are controversial. Institutions have different surgical approaches for the treatment of BOTs. Some surgeons prefer comprehensive surgical staging, including lymphatic sampling or dissection, while others exclude the lymph nodes [4, 7].

The purposes of the present study were to perform a retrospective review of the clinical characteristics, surgical management, and surgical outcomes, and to identify variables affecting survival in 733 patients with BOTs who were treated at ten gynecology departments in Turkey. We also sought to explore the following issues:

1) Is surgical staging (including lymphadenectomy) necessary in all patients?

2) Is appendectomy necessary in patients with mucinous BOTs?

3) Which type of procedure should the surgeon choose in patients with BOTs (radical vs. conservative)?

4) Should patients with BOTs receive adjuvant chemotherapy after the surgery if they have a tumor stage $\geq \mathrm{IC}$, as with epithelial ovarian tumors?

5) What is the function of analyzing frozen sections during BOT surgery? Do the results differ between serous and mucinous types?

6) What should the surgeon do in patients with recurrent BOTs?

7) What are the prognostic factors for overall and disease-free survival in patients with BOTs?

\section{Methods}

This retrospective study was performed using 10 gynecological oncology department databases (Izmir Tepecik Education and Research Hospital, Antalya Akdeniz University School of Medicine, Dicle University School of Medicine, Zekai Tahir Burak Education and
Research Hospital, Zonguldak Bulent Ecevit University School of Medicine, Antalya Education and Research Hospital, Zeynep Kamil Education and Research Hospital, Istanbul Bakırköy Sadi Konuk Education and Research Hospital, Sisli Hamidiye Etfal Education and Research Hospital, and Istanbul Education and Research Hospital). All patients with BOTs diagnosed between January 1, 1998 and December 31, 2014 were included.

This study was approved by the ethics committee. It was conducted in accordance with the ethical standards of the Declaration of Helsinki.

From the hospital databases, patient age, menopausal state, pre-operative CA-125, and preoperative ultrasound images were collected. Furthermore, the surgical technique, histological type, mean tumor diameter, lymph node status, stage at diagnosis, final pathological diagnosis, and accompanying pathologies, if any, were reviewed. Additionally, chemotherapy after surgery, postoperative followup periods, and data related to disease recurrence were evaluated. If frozen sections (FS) were analyzed intraoperatively, FS results were reported intraoperatively as benign, borderline tumor, at least borderline tumor, or malignant tumor. Patients with incomplete data were excluded from the analysis.

The International Federation of Gynecology and Obstetrics (FIGO) 2009 staging scheme for epithelial ovarian carcinomas was used in all patients [8]. Although the FIGO ovarian staging classification was revised on January 1, 2014, we used the previous staging classification for 2014 patients for consistency. Surgical procedures were classified as radical or conservative. If both ovaries were removed, this was included in the radical group. The conservative group included fertility sparing surgeries (such as unilateral salpingo-oophorectomy (USO), cystectomy, bilateral cystectomy, cystectomy with contralateral ovarian biopsy, and bilateral ovarian biopsies) in women who were premenopausal or wished to preserve their fertility. Moreover, patient operations were categorized into three groups: complete staging, incomplete staging, or unstaged procedures. Complete staging was defined as peritoneal washing and/or biopsies, pelvic and paraaortic lymphadenectomy (sampling or complete), and omentectomy being performed. If only peritoneal washing and omental and/or peritoneal biopsies without lymphadenectomy were performed, this was considered incomplete staging. Furthermore, if only ovarian surgery (only ovarian cystectomy or oopherectomy) was performed, this was considered unstaged. Additionally, if the patients underwent only an appendectomy with ovarian surgery, they were classified in the unstaged group.

Survival analysis was based on the Kaplan-Meier method and results were compared using the log-rank test. Disease-free survival (DFS) was defined as the time from the date of primary surgery to the detection of 
recurrence or the latest observation. Overall survival (OS) was defined as the time from the date of primary surgery to death or the latest observation. The $x^{2}$ test and Student's t-test for unpaired data were used for statistical analyses. Cox regression analysis was used to determine factors affecting survival, and results are presented as hazard ratios (HR). All statistical analyses were performed using the Med-Calc software (ver. 11.5 for Windows; MedCalc Software, Mariakerke, Belgium). A $p$ value $<0.05$ was considered to indicate statistical significance.

\section{Results}

We evaluated 733 patients with BOTs during the study period. The characteristics of the patients are shown in Table 1. There was recurrence in $69(9.4 \%)$ of the patients: $35(50.7 \%)$ in the conservative surgery group

Table 1 Demographic characteristics of patients with borderline ovarian tumors

\begin{tabular}{ll}
\hline Age & \\
Median $(n$, range in years) & $41.2(16-82)$ \\
$<40$ years $(n, \%)$ & $353(48.2)$ \\
$\geq 40$ years $(n, \%)$ & $380(51.8)$ \\
Postmenopausal status ( $n$, \%) & $227(31.0)$ \\
Histology & \\
Serous ( $n, \%)$ & $534(72.9)$ \\
Mucinous $(n, \%)$ & $160(21.8)$ \\
Other $(n, \%)$ & $39(5.3)$ \\
Ultrasound image & \\
Solid $(n, \%)$ & $110(15.0)$ \\
Cystic $(n, \%)$ & $130(17.7)$ \\
Unknown $(n, \%)$ & $493(67.3)$ \\
Median CA-125 level (U/mL) & $89(1-3394)$ \\
Median size (mm) & $112.02 \pm 64.57$ \\
Stage in diagnosis $(n, \%)$ & \\
IA & $516(70.4)$ \\
IB & $74(10.1)$ \\
IC & $64(8.7)$ \\
IIA & $2(0.3)$ \\
IIB & $6(0.8)$ \\
IIC & $8(1.1)$ \\
IIIA & 0 \\
IIIC & $55.2(1-216)$ \\
\hline Disease-free survival ( $n$, range in months) & $11(1.5)$ \\
\hline
\end{tabular}

and 34 (49.3\%) in the radical surgery group (the difference was not statistically significant, $p=0.405$ ) (Table 2 ). Furthermore no statistically significant difference in recurrence was observed between complete, incomplete, and unstaged patients $(9.6,12.3$, and $8.4 \%$, respectively; $p=0.615$ ). Most of the recurrent patients were treated with surgery; 10 were managed with chemotherapy, 47 were managed with surgery, and 12 were managed with chemotherapy after surgery. During the follow-up period, in total, $10(1.4 \%)$ patients died from their disease.

In 407 patients, frozen section analyses were carried out. Benign, borderline, at least borderline, and malignancies were seen in 30 (7.3\%), 251 (61.6\%), 117 $(16.0 \%)$, and $9(2.2 \%)$ patients, respectively. The accuracy of frozen section analyses in serous type tumors was significantly higher than in the mucinous type ( $94 \%$ vs. $80 \%$; $p<0.001$ ).

In total, 101 patients received adjuvant chemotherapy (CT). During the study period, postoperative CT was administered for FIGO stage IC and more advanced stages or recurrent disease. Of the 101 patients, 25 received CT for recurrent disease, 36 for early stage disease (stage IC or II, 36/76 patients), and 40 received CT for advanced-stage disease (stage III or IV, 40/76 patients). Postoperative CT regimens consisted of cisplatin + paclitaxel (37/101 patients), carboplatin + paclitaxel (55/101 patients), cisplatin + doxorubicin + cyclophosphamide (4/101 patients), cisplatin + cyclophosphamide (3/101 patients), and cisplatin + amifostin (2/101 patients) for 3-6 cycles.

Surgical characteristics of the patients are shown in Table 2. In total, 388 (52.9\%) patients underwent radical excision procedures, while 345 (47.1\%) underwent conservative surgical procedures. An appendectomy was performed in 289 (38.4 \%) cases. The number of patients with appendicial involvement was 23 (3.1\%); 21 of them were in the mucinous group (2.8\%).

We next analyzed the patients by dividing them into two groups according to the median age $(<40$ vs. $\geq 40)$. All parameters were similar between the groups (Table 3). The results of the multivariate analyses of DFS and OS are shown in Table 4. In the multivariate analysis, performance of surgical staging (or not), FIGO stage, age $(<40$ or $\geq 40)$, menopausal status, presence of an invasive implant, performance of radical surgery, lymphadenectomy, and adjuvant CT for tumor stage $\geq$ IC were not independent prognostic factors for DFS or OS (Table 4).

With a Kaplan-Meier analysis, we did not find any difference in DFS ( $\mathrm{HR}=0.96 ; 95 \% \mathrm{CI}=0.7-1.2 ; p=0.576$ ) or $\mathrm{OS}(\mathrm{HR}=0.9 ; 95 \% \mathrm{CI}=0.8-1.1 ; p=0.328)$ between patients who underwent conservative versus radical surgeries. There was also no difference in DFS $(\mathrm{HR}=0.74$; $95 \% \mathrm{CI}=0.8-1.1 ; p=0.080)$ or $\mathrm{OS}(\mathrm{HR}=0.8 ; 95 \%$ 
Table 2 Pathological and surgical characteristics of patients with borderline ovarian tumors

\begin{tabular}{|c|c|}
\hline \multicolumn{2}{|l|}{ Frozen pathology records $(n, \%)$} \\
\hline Benign & $30(7.3)$ \\
\hline Borderline & $251(61.6)$ \\
\hline At least borderline & $117(28.7)$ \\
\hline Malignant & $9(2.2)$ \\
\hline \multicolumn{2}{|l|}{ Accuracy of frozen pathology $(n, \%)^{*}$} \\
\hline Serous $(n, \%)$ & $288(94)$ \\
\hline Mucinous $(n, \%)$ & $67(80)$ \\
\hline \multicolumn{2}{|l|}{ Surgery Type $(n, \%)$} \\
\hline Conservative & $345(47.1)$ \\
\hline Radical & $388(52.9)$ \\
\hline \multicolumn{2}{|l|}{ Conservative surgery type $(n, \%)$} \\
\hline Unilateral cystectomy & $106(30.7)$ \\
\hline Bilateral cystectomy & $20(5.7)$ \\
\hline Cystectomy and contralateral ovarian biopsy & $7(2.0)$ \\
\hline Unilateral salpingo-oopherectomy (USO) & $194(56.2)$ \\
\hline USO and contralateral ovarian biopsy & $17(4.9)$ \\
\hline Bilateral ovarian biopsy & $1(0.2)$ \\
\hline \multicolumn{2}{|l|}{ Staging surgery $(n, \%)$} \\
\hline None & $273(37.2)$ \\
\hline \multicolumn{2}{|l|}{ Yes } \\
\hline Complete & $395(53.9)$ \\
\hline Incomplete & $65(8.9)$ \\
\hline Received postoperative chemotherapy & $101(13.8)$ \\
\hline Appendectomy $(n, \%)$ & $289(39.4)$ \\
\hline Appendectomy with serous histology & 159 \\
\hline Appendectomy with mucinous histology & 130 \\
\hline Appendicial involvement $(n, \%)$ & $23(3.1)$ \\
\hline Appendicial involvement + mucinous type & $21(2.8)$ \\
\hline Hysterectomy $(n, \%)$ & $436(59.5)$ \\
\hline $\begin{array}{l}\text { Median removed lymph nodes } \\
\text { ( } n \text {, range in numbers) }\end{array}$ & $25.7 \pm 22.2(2-173)$ \\
\hline \multicolumn{2}{|l|}{ Surgery type (n, \%) } \\
\hline Laparascopy & $34(4.6)$ \\
\hline Laparotomy & $699(95.4)$ \\
\hline Recurrence $(n, \%)$ & $69(9.4)$ \\
\hline \multicolumn{2}{|l|}{ Treatment after recurrence ${ }^{* *}$} \\
\hline Surgery & $47(6.4)$ \\
\hline Chemotherapy & $10(1.4)$ \\
\hline Surgery + Chemotherapy & $12(1.6)$ \\
\hline \multicolumn{2}{|l|}{ Recurrence $(n, \%)^{* * *}$} \\
\hline Conservative group & $35(10.5)$ \\
\hline Radical group & $34(8.7)$ \\
\hline
\end{tabular}

Table 2 Pathological and surgical characteristics of patients with borderline ovarian tumors (Continued)

\begin{tabular}{ll}
\hline Recurrence $(n, \%)^{* * *}$ & \\
Unstaging & $23(8.4)^{* * *}$ \\
Incomplete staging & $8(12.3)$ \\
Complete staging & $38(9.6)$
\end{tabular}

${ }^{*} P<0.001$

$* * P<0.001$

***P $=0.405$

${ }^{* * * *} P=0.615$

$\mathrm{CI}=0.7-1.0 ; p=0.091)$ between complete, incomplete, and unstaged patients. When the impact of lymph node sampling or dissection on DFS and OS was assessed, lymph node removal had no effect on DFS $(\mathrm{HR}=1.2 ; 95 \% \mathrm{CI}=0.9-1.4 ; p=0.465)$ or $\mathrm{OS}(\mathrm{HR}=1.1$; $95 \% \mathrm{CI}=1.0-1.3 ; p=0.623)$. Furthermore, there was no difference in DFS $(\mathrm{HR}=1.3 ; 95 \% \mathrm{CI}=1.1-1.5 ; p=0.410)$ or $\mathrm{OS}(\mathrm{HR}=0.8 ; 95 \% \mathrm{CI}=0.6-1.1 ; p=0.856)$ between patients treated with surgery alone, chemotherapy alone, or sequential treatment for recurrent BOT. Similarly, in patients who underwent cystectomies or oopherectomies, there was no difference in DFS $(\mathrm{HR}=0.8 ; 95 \% \mathrm{CI}=$ $0.7-1.1 ; p=0,132)$ or $\mathrm{OS}(\mathrm{HR}=0.7 ; 95 \% \mathrm{CI}=0.6-0.8$; $p=0.212$ ). In BOTs, adding an appendectomy to the surgical procedure had no effect on DFS $(\mathrm{HR}=0.9$; $95 \% \mathrm{CI}=0.7-1.1 ; p=0.270)$ or $\mathrm{OS}(\mathrm{HR}=1.0 ; 95 \%$ $\mathrm{CI}=0.7-1.3 ; p=0.320)$. In patients who underwent hysterectomies (vs. not), there was no also no difference in DFS $(\mathrm{HR}=1.1 ; 95 \% \mathrm{CI}=0.9-1.2 ; p=0.208)$ or $\mathrm{OS}(\mathrm{HR}=1.4 ; 95 \% \mathrm{CI}=1.1-1.7 ; p=0,416)$. Finally, performing (vs. not) an appendectomy in mucinous BOT patients had no effect on DFS $(\mathrm{HR}=0.9 ; 95 \%$ $\mathrm{CI}=0.7-1.3 ; p=0.990)$ or $\mathrm{OS}(\mathrm{HR}=0.8 ; 95 \% \mathrm{CI}=$ $0.6-0.9 ; p=0.751)$.

We also analyzed the patients by dividing them into two groups according to recurrence (vs. not). All parameters were similar between groups (Table 5). The results of univariate and multivariate analyses for recurrence are shown in Table 5 . In univariate and multivariate analyses, age (<40 vs. $\geq 40)$, FIGO stage ( $\geq$ IC vs. $<$ IC), performance of radical surgery, and performance of surgical staging (vs. not) were not independent risk factors for the recurrence of BOTs (Table 6).

\section{Discussion}

In this study, we performed a retrospective analysis of 733 patients with BOTs who were treated with surgery at 10 gynecology centers in Turkey. BOTs are classified as a separate entity within ovarian malignancies because of their atypical properties. Furthermore, they are not a rare clinical entity, constituting $\sim 10-20 \%$ of all ovarian neoplasias in clinical studies [3]. The present study is one of the largest reported series of cases with BOTs. 
Table 3 Clinical details of patients based on age

\begin{tabular}{|c|c|c|c|c|}
\hline & Age $<40(n=353)$ & Age $\geq 40(n=380)$ & $P$ value & RR $(95 \% \mathrm{Cl})$ \\
\hline$\overline{\text { Serous histology }}{ }^{a}$ & $262(74.1)$ & $272(71.6)$ & 0.723 & \\
\hline Complete surgery $^{a}$ & 189 (53.5) & $206(54.2)$ & 0.448 & \\
\hline Radical surgery ${ }^{a}$ & $184(52.1)$ & $204(53.7)$ & 0.673 & $1.0(0.7-1.4)$ \\
\hline Appendectomy ${ }^{a}$ & $145(41.1)$ & $144(37.9)$ & 0.378 & $1.0(0.9-1.2)$ \\
\hline Stage $\left.\right|^{a}$ & $311(88.1)$ & $343(90.2)$ & 0.782 & \\
\hline$O S^{b}$ & $57.7 \pm 42.1$ & $52.9 \pm 43.4$ & 0.419 & \\
\hline $\mathrm{DFS}^{\mathrm{b}}$ & $53.5 \pm 39.7$ & $50.0 \pm 40.7$ & 0.390 & \\
\hline Recurrence ${ }^{a}$ & $33(9.3)$ & $36(9.5)$ & 0.954 & $0.9(0.6-1.5)$ \\
\hline
\end{tabular}

OS overall survival, DFS disease-free survival

Data are expressed as ${ }^{a}: n(\%),{ }^{b}:$ mean \pm standard deviation

Similar to previous studies, the mean age of patients with BOTs was 41.2 years in our study. Of the 733 patients with the tumor, $353(48.1 \%)$ were $<40$ years old; our result adds to current knowledge on the occurrence of BOTs in younger and premenopausal women [9-11]. Furthermore, we found that clinical features were similar between the groups aged under and over 40 years. Consistent with previous studies $[11,12]$, the most common histological type was a serous BOT in the present study. However, the rate of serous histology (72.9 \%) was significantly higher than in several previous studies $[13,14]$. Heterogeneity of the mucinous tumors may be a reason for this.

The most commonly discussed questions about BOTs are as follows. We address each in turn.

1) Is surgical staging (including lymphadenectomy) necessary in all patients?

In our study, more than half of our patients were staged surgically, and most of them were staged completely, similar to the ovarian cancer surgery situation. However, we found no difference between the survival rates of staged and unstaged patients. Furthermore, no difference was found between completely and incompletely staged patients.
These results were similar to previous studies [13-15]. We found that lymph node removal in surgical staging did not affect survival, as in Güvenal et al.'s study [13]. Similarly, Fauvet et al. suggested that lymph node removal is not a part of surgical staging for BOTs [7].

2) Is appendectomy necessary in patients with mucinous BOTs?

Adding an appendectomy to surgical staging procedures has been recommended for mucinous tumors, in particular [4]. In our study, $40 \%$ of cases underwent appendectomies. We found that an appendectomy had no impact on survival in mucinous or other types of BOT. Thus, it is not necessary to perform an appendectomy routinely in patients with mucinous BOTs, according to our findings. Kleppe et al.'s and Lin et al.'s studies reached the same conclusion $[16,17]$.

3) Which type of procedure (radical vs. conservative) should the surgeon choose in patients with BOTs? There is an important and controversial issue about surgical approaches in diagnosed BOT patients, especially in women who wish to preserve their reproductive status. Many previous studies $[13,18]$ have suggested that patients who undergo

Table 4 Results of multivariate analyses of disease-free survival and overall survival

\begin{tabular}{|c|c|c|c|c|c|c|}
\hline & \multicolumn{3}{|c|}{ Disease-free survival } & \multicolumn{3}{|c|}{ Overall survival } \\
\hline & Hazard ratio & $95 \% \mathrm{Cl}$ & $P$ value & Hazard ratio & $95 \% \mathrm{Cl}$ & $P$ value \\
\hline Age $(<40$ vs. $\geq 40)$ & 1.0 & $0.8-1.2$ & 0.67 & 1.0 & $0.8-1.2$ & 0.61 \\
\hline Stage (I/II vs. III/IV) & 0.9 & $0.9-1.0$ & 0.39 & 0.9 & $0.9-1.0$ & 0.86 \\
\hline Radical surgery & 1.0 & $0.9-1.0$ & 0.25 & 1.0 & $0.9-1.0$ & 0.64 \\
\hline Staging surgery & 1.0 & $0.9-1.0$ & 0.10 & 1.0 & $0.9-1.1$ & 0.052 \\
\hline Menopause & 0.9 & $0.8-1.2$ & 0.95 & 1.0 & $0.8-1.3$ & 0.57 \\
\hline Invasive implant & 0.8 & $0.6-1.2$ & 0.47 & 0.8 & $0.6-1.2$ & 0.51 \\
\hline Lymph node dissection & 0.9 & $0.9-1.1$ & 0.08 & 0.8 & $0.7-1.1$ & 0.08 \\
\hline Adjuvant chemotherapy (tumorstage $\geq I C$ ) & 0.8 & $0.6-1.0$ & 0.06 & 0.9 & $0.8-1.1$ & 0.07 \\
\hline
\end{tabular}


Table 5 Characteristics of patients based on recurrence

\begin{tabular}{|c|c|c|c|c|}
\hline & $\begin{array}{l}\text { Recurrence } \\
(n=69)\end{array}$ & $\begin{array}{l}\text { No recurrence } \\
(n=664)\end{array}$ & $P$ value & RR $(95 \% \mathrm{Cl})$ \\
\hline Age (years) ${ }^{a}$ & $41.5 \pm 13.8$ & $39.0 \pm 12.4$ & 0.146 & \\
\hline Tumor size $(\mathrm{mm})^{\mathrm{a}}$ & $113.5 \pm 65.1$ & $93.5 \pm 53.8$ & 0.094 & \\
\hline Surgery type ${ }^{b}$ & & & 0.470 & $0.6(0.1-2.4)$ \\
\hline Laparascopy & $2(5.9)$ & $32(94.1)$ & & \\
\hline Laparatomy & $67(9.6)$ & $632(90.4)$ & & \\
\hline Stage ${ }^{b}$ & & & 0.129 & $0.6(0.4-1.1)$ \\
\hline$\geq I C$ & 18 (12.6) & $125(87.4)$ & & \\
\hline$<\mathrm{IC}$ & $50(8.5)$ & $540(91.5)$ & & \\
\hline Radical Surgery & & & 0.405 & $1.2(0.7-1.9)$ \\
\hline Yes & $34(8.8)$ & 354 (91.2) & & \\
\hline No & $35(10.2)$ & $310(89.8)$ & & \\
\hline
\end{tabular}

conservative surgery have higher recurrence rates than the radical surgery group. Güvenal et al.'s study showed that patients who underwent radical surgery had a $3 \%$ recurrence rate, whereas in patients who underwent fertility sparing surgeries, the recurrence rate was $8.3 \%$ [13]. Furthermore, Boran et al. reported that patients who underwent radical surgery had no recurrence, whereas in patients who underwent conservative surgery, the recurrence rate was $6.5 \%$ [18]. In contrast, we found that the rate of recurrence between the two groups was not different $(35 / 345,10.5 \%$ vs. 34/388, $8.7 \% ; p=0.405)$. Furthermore, we found that radical surgery was not an independent prognostic factor for DFS or OS. Thus, we considered that performing radical surgery makes no sense with regard to recurrence in BOT patients. We attribute these findings to the follow-up period of our study, which was much longer than those of other studies (e.g., Boran et al. and Güvenal et al.). Ayhan et al., suggested that patients with BOTs can be treated safely with conservative surgery [11]. In the present study, we found that surgical procedure (radical vs. conservative) was not an independent prognostic factor for DFS or OS. These findings were similar to those of previous studies $[13,18,19]$. We also demonstrated that hysterectomy had no impact on survival in BOT patients, similar to Menczer et al.'s study [20].

4) Should patients with BOTs receive adjuvant chemotherapy after surgery if they have a tumor of stage $\geq \mathrm{IC}$, as with epithelial ovarian tumors? Based on the literature, the use of adjuvant chemotherapy for BOTs remains controversial. According to the National Comprehensive Cancer Network (NCCN), the treatment recommendation after comprehensive staging depends on the presence or absence of invasive implants. The initial therapeutic approach in patients having invasive implants may include observation; alternatively, consideration can be given to treating patients according to the guidelines for epithelial ovarian cancer (category 2B for adjuvant chemotherapy) [21]. In the present study, surgery followed by chemotherapy did not show a different survival rate compared to no adjuvant chemotherapy in advanced-stage BOTs. This finding is similar to that of Trope et al. [22]. Most of the recurrence patients were treated with surgery alone in our

Table 6 Results of univariate and multivariate analyses of risk factors of patients with recurrent BOTs

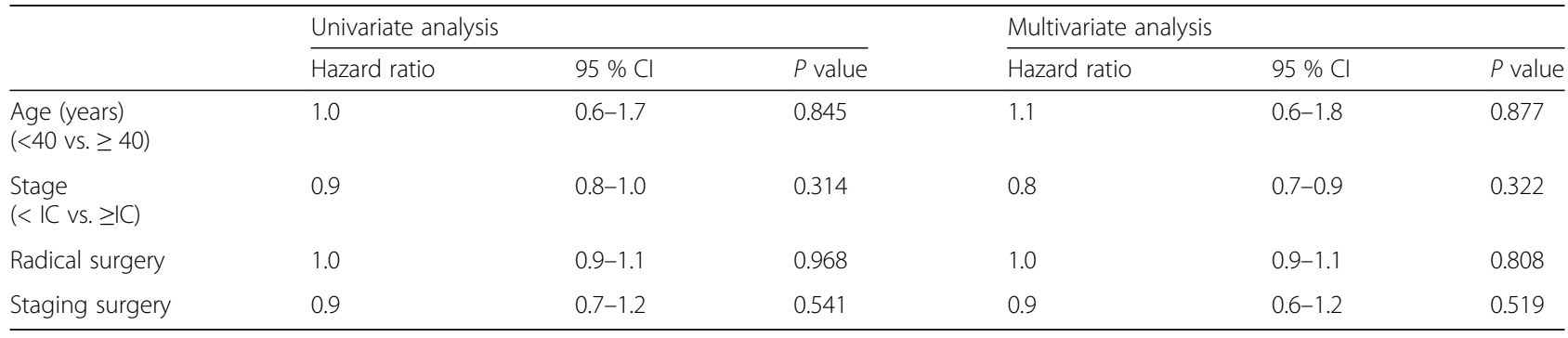


study, but we found no significant difference in DFS or OS in recurrent patients treated with surgery alone, chemotherapy alone, or sequential treatment.

5) What is the role of frozen section analyses during BOT surgery? Do the results differ between serous and mucinous BOTs?

An accurate intraoperative diagnosis is important in the management of BOTs during the intra- and postoperative periods. Reported accuracy rates have varied widely, from 50 to $85 \%$. In this study, the accuracy of frozen section analysis was $90.4 \%$, slightly higher than many previous studies [23, 24]. One reason may be that there were fewer mucinous tumors in the present study, because mucinous histology has been reported to be associated with low sensitivity in frozen section analyses in past studies $[25,26]$. Similarly, in the present study, the accuracy for serous tumors was $94 \%$ versus $80 \%$ for mucinous tumors $(p<0.001)$.

6) What should the surgeon do for patients with recurrent BOTs?

We found no significant difference in DFS or OS rates in recurrent patients managed with secondary surgery, chemotherapy, or sequential treatment $(\mathrm{HR}=1.3 ; 95 \% \mathrm{CI}=1.1-1.5 ; p=0.410$ and $\mathrm{HR}=0.8 ; 95 \% \mathrm{CI}=0.6-1.1 ; p=0.856$, respectively). Furthermore we showed that age (<40 vs. $\geq 40)$, FIGO stage ( $<$ IC vs. $\geq$ IC), performance of radical surgery, and performance of surgical staging (vs. not) were not independent risk factors for recurrence of BOTs. In contrast, Ren et al. reported that a conservative surgical procedure was an independent risk factor for recurrence. Additionally, Sumin et al. reported that age was an independent risk factor for recurrence [12, 27]. One reason for these differences may be that our study included more participants than the other studies.

7) What are the prognostic factors for overall and disease-free survival in BOTs?

We found that surgical staging (vs. not), FIGO stage, age ( $<40$ vs. $\geq 40)$, menopausal status, the presence of an invasive implant, radical (vs. conservative) surgery, lymph node dissection (vs. not), and undergoing adjuvant $\mathrm{CT}$ for a tumor of stage $\geq \mathrm{IC}$ were not independent prognostic factors for DFS or OS. Our results are similar to many previous studies [13, 14, 28]. In addition to our findings, Güvenal et al. suggested that appendectomy was not an independent prognostic factor for DFS or OS.

This study has several limitations. First, it was a retrospective analysis of patients from various institutions. Second, there were many different clinical approaches. Third, the absence of some data and the histopathological evaluations of BOTs may vary depending on the experience of the institutions. Despite these limitations, this study represents one of the largest series of cases with BOTs, as a 10-center study. Moreover, the availability of good follow-up data increased the validity of the results and mitigated the weaknesses.

\section{Conclusions}

In conclusion, patients undergoing conservative surgeries did not have higher recurrence rates, and survival time was not shortened. Detailed surgical staging, including lymph node sampling or dissection, appendectomy, and hysterectomy did not cause any difference in survival rates. Age and radical surgery were not independent prognostic factors for DFS. Thus, our findings suggest that radical surgery and comprehensive surgical staging should not be routinely performed in BOT patients. We believe that this study shows important findings due to its multicentric and long-term nature. Although this study was a retrospective analysis, we believe that it provides useful information for prospective randomized controlled trials in the future.

\section{Abbreviations \\ BOTs: Borderline ovarian tumors; FIGO: International Federation of Gynecology and Obstetrics \\ Acknowledgements \\ No. \\ Funding \\ This paper was written without any funding sources. \\ Availability of data and materials \\ All dataset on which the conclusions are based upon are deposited and presented in the article. \\ Authors' contributions \\ All authors contributed to the development of the review, the design of the figures and in writing the manuscript. OA and KG participated in the design of the study and performed the statistical analysis. MG,TG, AK, TS, OG, BA, NC,IAO, LY, MS, GP, ZFC, TT, MMM, RÖ, EA, OE, AT, VG, MSI, HG, MY, AS, TŞ, $\mathrm{MH}, \mathrm{BB}, \mathrm{ADU}$ conceived of the study, and participated in its design and coordination and helped to draft the manuscript. All authors read and approved the final manuscript.}

\section{Competing interests}

The authors declare that they have no competing interests.

Consent for publication

Not applicable.

Ethics approval and consent to participate

All subjects have signed informed consents. This study was approved by Ethics Committee of Tepecik Education and Research Hospital.

\section{Author details}

${ }^{1}$ Department of Gynecology and Gynecologic Oncology, Izmir Tepecik Education and Research Hospital, Izmir, Turkey. ${ }^{2}$ Department of Gynecology and Gynecologic Oncology, Mugla Sıtkı Kocman University Education and Research Hospital, Mentese 48000, Mugla, Turkey. ${ }^{3}$ Department of Gynecology and Gynecologic Oncology, Sisli Hamidiye Etfal Education and Research Hospital, Istanbul, Turkey. ${ }^{4}$ Department of Gynecology and Gynecologic Oncology, Zekai Tahir Burak Education and Research Hospital, 
Ankara, Turkey. ${ }^{5}$ Department of Gynecology and Gynecologic Oncology, Zeynep Kamil Education and Research Hospital, Istanbul, Turkey. ${ }^{6}$ Department of Gynecology and Gynecologic Oncology, Akdeniz University School of Medicine, Antalya, Turkey. ${ }^{7}$ Department of Gynecology and Gynecologic Oncology, Istanbul Education and Research Hospital, Istanbul, Turkey. ${ }^{8}$ Department of Gynecology and Gynecologic Oncology, Dicle University School of Medicine, Diyarbakır, Turkey. ${ }^{9}$ Department of Gynecology and Gynecologic Oncology, Bakırköy Dr. Sadi Konuk Education and Research Hospital, Istanbul, Turkey. ${ }^{10}$ Department of Gynecology and Gynecologic Oncology, Antalya Education and Research Hospital, Antalya, Turkey. ${ }^{11}$ Department of Gynecology and Gynecologic Oncology, Zonguldak Bulent Ecevit University School of Medicine, Zonguldak, Turkey.

\section{Received: 1 August 2016 Accepted: 9 October 2016}

Published online: 18 October 2016

\section{References}

1. Taylor H. Malignant and semi-malignant tumors of the ovary. Surg Gynecol Obstet. 1929;48:204-30.

2. Hart WR, Norris HJ. Borderline and malignant mucinous tumors of the ovary. Histologic criteria and clinical behavior. Cancer. 1973;31:1031-45.

3. Tinelli R, Tinelli A, Tinelli FG, Cicinelli E, Malvasi A. Conservative surgery for borderline ovarian tumors: a review. Gynecol Oncol. 2006;100:185-91.

4. Gershenson DM. Clinical management potential tumours of low malignancy. Best Pract Res Clin Obstet Gynaecol. 2002;16(4):513-27.

5. Medeiros LR, Rosa DD, da Rosa MI, Bozzetti MC. Accuracy of CA 125 in the diagnosis of ovarian tumors: a quantitative systematic review. Eur J Obstet Gynecol Reprod Biol. 2009;142(2):99-105.

6. Timmerman D, Van Calster B, Testa AC, Guerriero S, Fischerova D, Lissoni AA, et al. Ovarian cancer prediction in adnexal masses using ultrasound-based logistic regression models: a temporal and external validation study by the IOTA group. Ultrasound Obstet Gynecol. 2010;36(2):226-34

7. Fauvet R, Boccara J, Dufournet C, David-Montefiore E, Poncelet C, Daraï E. Restaging surgery for women with borderline ovarian tumors: results of a French multicenter study. Cancer. 2004;100:1145.

8. Benedet JL, Bender H, Jones 3rd H, Ngan HY, Pecorelli S. FIGO staging classifications and clinical practice guidelines in the management of gynecologic cancers. FIGO Committee on Gynecologic Oncology. Int J Gynaecol Obstet. 2000;70(2):209-62.

9. Gotlieb WH, Chetrit A, Menczer J, Hirsh-Yechezkel G, Lubin F, Friedman E, et al. Demographic and genetic characteristics of patients with borderline ovarian tumors as compared to early stage invasive ovarian cancer. Gynecol Oncol. 2005:97(3):780-3.

10. Romagnolo C, Gadducci A, Sartori E, Zola P, Maggino T. Management of borderline ovarian tumors: results of an Italian multicenter study. Gynecol Oncol. 2006;101(2):255-60

11. Ayhan A, Guvendag Guven ES, Guven S, Kucukali T. Recurrence and prognostic factors in borderline ovarian tumors. Gynecol Oncol. 2005;98(3):439-45.

12. Ren J, Peng Z, Yang K. A clinicopathologic multivariate analysis affecting recurrence of borderline ovarian tumors. Gynecol Oncol. 2008;110(2):162-7.

13. Guvenal T, Dursun P, Hasdemir PS, Hanhan M, Guven S, Yetimalar H, et al. Effect of surgical staging on 539 patients with borderline ovarian tumors: a Turkish Gynecologic Oncology Group study. Gynecol Oncol. 2013;131(3): 546-50.

14. Winter WE, Kucera PR, Rodgers W, McBroom J, Olsen C, Maxwell L. Surgical staging in patients with ovarian tumours of low malignant potential. Obstet Gynecol. 2002;100:671-6.

15. Tinelli R, Malzoni M, Cosentino F, Perone C, Tinelli A, Malvasi A, Cicinelli E. Feasibility, safety, and efficacy of conservative laparoscopic treatment of borderline ovarian tumors. Fertil Steril. 2009:92(2):736-41.

16. Kleppe M, Bruls J, Van Gorp T, Massuger L, Slangen BF, Van de Vijver KK, et al. Mucinous borderline tumours of the ovary and the appendix: a retrospective study and overview of the literature. Gynecol Oncol. 2014; 133(2):155-8

17. Lin JE, Seo S, Kushner DM, Rose SL. The role of appendectomy for mucinous ovarian neoplasms. Am J Obstet Gynecol. 2013;208(46):e1-4.

18. Boran N, Cil AP, Tulunay G, Ozturkoglu E, Koc S, Bulbul D, et al. Fertility and recurrence results of conservative surgery for borderline ovarian tumors. Gynecol Oncol. 2005;97:845.
19. Gungor T, Cetinkaya N, Yalcin H, Ozdal B, Ozgu E, Baser E, et al. Retrospective evaluation of borderline ovarian tumors: single center experience of 183 cases. Arch Gynecol Obstet. 2015;291(1):123-30.

20. Menczer J, Chetrit A, Sadetzki S, Anderma S, Alteras M, Anteby S, et al. The effect of hysterectomy on survival of patients with borderline ovarian tumors. Gynecol Oncol. 2012;125(2):372-5.

21. NCCN. Clinical Practice Guidelines in Oncology Ovarian Cancer. Including Fallopian Tube Cancer and Primary Peritoneal Cancer Version 2. 2015.

22. Trope CG, Kaern J, Davidson B. Borderline ovarian tumours. Best Pract Res Clin Obstet Gynaecol. 2013;26(3):325-36.

23. Ilvan S, Ramazanoglu R, Ulker Akyildiz E, Calay Z, Bese T, Oruc N. The accuracy of frozen section (intraoperative consultation) in the diagnosis of ovarian masses. Gynecol Oncol. 2005;97(2):395-9.

24. Shih KK, Garg K, Soslow RA, Chi DS, Abu-Rustum NR, Barakat RR. Accuracy of frozen section diagnosis of ovarian borderline tumor. Gynecol Oncol. 2011; 123(3):517-21.

25. Tempfer CB, Polterauer S, Bentz EK, Reinthaller A, Hefler LA. Accuracy of intraoperative frozen section analysis in borderline tumors of the ovary: a retrospective analysis of 96 cases and review of the literature. Gynecol Oncol. 2007;107(2):248-52.

26. Pongsuvareeyakul T, Khunamornpong S, Settakorn J, Sukpan K, Suprasert $P$, Siriaunkgul S. Accuracy of frozen-section diagnosis of ovarian mucinous tumors. Int J Gynecol Cancer. 2012;22:400-6.

27. Oh S, Kim R, Lee YK, Kim JW, Park NH, Song YS. Clinicopathological aspects of patients with recurrence of borderline ovarian tumors. Obstet Gynecol Sci. 2015;58(2):98-105.

28. Desfeux P, Camatte S, Chatellier G, Blanc B, Querleu D, Lécuru F. Impact of surgical approach on the management of macroscopic early ovarian borderline tumors. Gynecol Oncol. 2005;98(3):390-5.

\section{Submit your next manuscript to BioMed Central and we will help you at every step:}

- We accept pre-submission inquiries

- Our selector tool helps you to find the most relevant journal

- We provide round the clock customer support

- Convenient online submission

- Thorough peer review

- Inclusion in PubMed and all major indexing services

- Maximum visibility for your research

Submit your manuscript at www.biomedcentral.com/submit
) Biomed Central 